\title{
Short Communication: Identification of Two Polymorphisms in the Goat Lipoprotein Lipase Gene and Their Association with Milk Production Traits
}

\author{
B. Badaoui, ${ }^{\star}$ J. M. Serradilla,† A. Tomàs, ${ }^{\star}$ B. Urrutia,‡ J. L. Ares,† J. Carrizosa,‡ A. Sànchez, \\ J. Jordana, ${ }^{*}$ and M. Amills*1 \\ *Departament de Ciència Animal, Facultat de Veterinària, Universitat Autònoma de Barcelona, Bellaterra 08193, Spain \\ †Departamento de Producción Animal, Campus de Rabanales, Universidad de Córdoba, 14071 Córdoba, Spain \\ ‡Instituto Murciano de Investigación y Desarrollo Agrario y Alimentario (IMIDA), Estación Sericícola, La Alberca, Murcia, Spain
}

\begin{abstract}
Lipoprotein lipase (LPL) is a glycoprotein that plays a central role in plasma triglyceride metabolism by hydrolyzing triglyceride-rich chylomicrons and very low density lipoproteins. The activity of milk LPL has been shown to differ among several goat breeds, suggesting the existence of a genetic polymorphism influencing the functional properties of this enzyme. We have characterized the complete coding sequence of the goat $L P L$ gene in 18 individuals belonging to 3 breeds. The coding region of the goat $L P L \mathrm{cDNA}$ was $1,437 \mathrm{bp}$ long and encoded a protein of 478 amino acids. Moreover, we have identified 2 single nucleotide polymorphisms (SNP) including a G50C missense mutation, which involved a Ser $\rightarrow$ Thr amino acid replacement at position 17 of the signal peptide, and a C2094T substitution in the $3^{\prime}$ untranslated region. A univariate mixed model was used to evaluate the association between $L P L$ genotypes and milk production and composition in 130 Murciano-Granadina goats. The G50C SNP was suggestively associated with milk fat content and tended to affect the milk dry weight basis. The C2094T SNP was not associated with any of the measured traits.
\end{abstract}

Key words: lipoprotein lipase, milk fat, MurcianoGranadina goat

The hydrolysis of milk fat globule triglycerides into free fatty acids is carried out by lipoprotein lipase (LPL), a $56-\mathrm{kDa}$ enzyme that also plays a key role in regulating the levels of plasma lipoproteins in the adipose and muscular tissues as well as in other body compartments such as liver, heart, nervous system, and mammary gland (Barber et al., 1997; Merkel et

Received June 30, 2006.

Accepted February 8, 2007.

${ }^{1}$ Corresponding author: Marcel.Amills@uab.es al., 2002). In goats, milk LPL activity is influenced by the stage of lactation, milking frequency, fasting, and lipid supplementation (Chilliard et al., 2003). Moreover, there are pieces of evidence that pinpoint the existence of genetic factors affecting LPL function. In this way, there are substantial differences in the activity of this enzyme as well as in the levels of spontaneous lipolysis in Norwegian, Alpine, and Saanen goats. More importantly, these 2 biochemical parameters were positively modified by selection for milk flavor in Norwegian goats (Chilliard et al., 2003). These findings are not surprising because in humans about 100 mutations have been identified in the $L P L$ gene, and a significant proportion of them are associated with the occurrence of familial combined hyperlipidemia and atherosclerosis due to a reduction or loss of LPL function (Merkel et al., 2002).

The nucleotide sequences of the bovine (Senda et al., 1987) and ovine (Edwards et al., 1993; Bonnet et al., 2000) $L P L$ cDNA have been described. Their coding regions are approximately $1.4 \mathrm{~kb}$ long and encode a protein of 478 AA. Moreover, the investigation of the levels of genetic diversity in the bovine $L P L$ gene has led to the identification of Sau96I (Tank and Pomp, 1994) and BsmAI (Lien et al., 1995) RFLP. The main objective of the current work was the characterization of the nucleotide sequence of the goat $L P L$ cDNA. Furthermore, we were interested in investigating if genetic variation at this locus has any influence on milk quality as well as on cheese manufacture parameters.

The molecular analysis of the goat $L P L$ cDNA involved isolation of total RNA from 18 goat liver samples, as previously described (Amills et al., 2003). Total cDNA was synthesized from $2 \mu \mathrm{g}$ of total RNA with the Thermoscript RT-PCR kit (Invitrogen, Barcelona, Spain). Four overlapping fragments (PCR1 to 4) encompassing the complete coding sequence of the goat $L P L$ gene were amplified with primers listed in Table 1. Polymerase chain reactions included $5 \mu \mathrm{L}$ of PCR 
Table 1. Annealing temperatures $\left(\mathrm{T}_{\mathrm{ann}}\right)$ and sequences of primers used in the sequencing and genotyping of the goat lipoprotein lipase gene ${ }^{1}$

\begin{tabular}{llc}
\hline PCR & \multicolumn{1}{c}{ Primer sequence } & $\mathrm{T}_{\text {ann }},{ }^{\circ} \mathrm{C}$ \\
\hline PCR1 & LPL-fragm1-FW, 5'-AAA CCT GCC GCT TCT AGC TC-3' & 57.8 \\
& LPL-fragm1-RV, 5'-TGG AGT CTG GTT CCC TCT TG-3' & \\
PCR2 & LPL-fragment2-FW; 5'-CTC AGG ACT CCC GAA GAC AC-3' & 62.2 \\
& LPL-fragment2-RV; 5'-AAG GGA TGT TCT CGC TCT CA-3' & \\
PCR3 & LPL-fragment3-FW, 5'-GTT GCA ACA ACA TGG GCT AC-3' & 61 \\
& LPL-fragment3-RV; 5'-TGT TCA CTC ACT CTT GAC TAG TTG T-3' & \\
PCR4 & LPL-fragm4-FW, 5'-GAA TGA AGT AAC TTT TAC AAA AGA CG-3' & 66 \\
& LPL-fragm4-RV, 5'-CAT GCT CGA AGT CTG ACT GAA-3' & 61 \\
PCR5 & G50CFW, 5'-CTC GGG CTC AGC GGT TCT AC-3' & 6 \\
PCR6 & G50CRV, 5'-CAG CCC TCC GTG GGA GAC-3' & 58.7 \\
& C2094TFW, 5'-AGG GTG AAC CAG GAA CTA GTG ACT-3' & \\
\hline
\end{tabular}

${ }^{1}$ Primer locations with regard to sequence DQ370053 were: LPL-fragm1-RV (432-451), LPL-fragment2FW (259-278), LPL-fragment2-RV (1245-1264), LPL-fragment3-FW (1058-1077), LPL-fragm4-FW (16081633), G50CFW (45-64), G50CRV (181-198), C2094TFW (2080-2103), C2094TRV (2317-2340). LPL-fragm1FW, LPL-fragment3-RV and LPL-fragm4-RV are external primers, and consequently, they are not included in the sequence DQ370053.

buffer, $1.5 \mu \mathrm{L}$ of $\mathrm{MgCl}_{2}(50 \mathrm{mM}), 1 \mu \mathrm{L}$ of $\operatorname{dNTP}(5 \mathrm{mM})$, $0.5 \mu \mathrm{L}$ of each primer $(50 \mu M), 3 \mu \mathrm{L}$ of $\mathrm{cDNA}$ (from a $12-\mu \mathrm{L}$ reverse transcription reaction) and $0.25 \mu \mathrm{L}$ of Taq DNA polymerase (5 U/ $\mu \mathrm{L}$; Ecogen S.R.L., Barcelona, Spain) in a final $50-\mu \mathrm{L}$ volume. The thermal profile consisted of 35 cycles of $94^{\circ} \mathrm{C}$ for $45 \mathrm{~s}$, annealing temperature (Table 1) for $30 \mathrm{~s}$ and $72^{\circ} \mathrm{C}$ for $45 \mathrm{~s}$. Amplified products were sequenced and analyzed according to Amills et al. (2003). Genomic DNA was extracted from goat peripheral blood mononuclear cells according to Amills et al. (2004). The primers used for the amplification of the fragments containing the 2 polymorphisms are indicated in Table 1: G50CFW and G50CRV for the G50C polymorphism (PCR5) and C2094TFW and C2094TRV for the C2094T polymorphism (PCR6). Thermal profiles and PCR conditions were as reported earlier; annealing temperatures are shown in Table 1 . The PCR products were purified with the ExoSAP-IT kit (Amersham Biosciences Europe $\mathrm{GmbH}$, Barcelona, Spain) and typed with the SnaPshot ddNTP Primer Extension kit (Applied Biosystems, Foster City, CA) according to the manufacturer's instructions. The extension primers used in this typing procedure were LPLEXON1; GAG CGT GTG GCT GCA GA (for typing G50C), and LPLE3'UTR; GTT ACA AAT TAA AGG AGA TAT ATA AAG TTG AGA T (for typing C2094T). The allelic frequencies of the 2 polymorphisms were calculated in a representative sample of 300 goats from the Murciano-Granadina breed and 117 goats from diverse breeds including Majorera $(n=20)$, Malagueña $(n=16)$, Saanen $(n=$ 16), Teramana $(n=15)$, Tinerfeña $(n=15)$, Palmera $(\mathrm{n}=15)$, and Alpine $(\mathrm{n}=20)$. An association study was performed by recording 14 parameters related to milk production and quality as well as with cheese manufac- ture in 130 Murciano-Granadina goats, as previously described (Badaoui et al., 2007). The $\alpha_{\mathrm{S} 1}{ }^{-} \mathrm{CN}$ genotype of these goats was determined according to the methods described by Amills (1996) and Ramunno et al. (2000). The statistical procedures used in the association study followed the methodology reported by Badaoui et al. (2007). The only modification that we performed was to include the $\alpha_{\mathrm{S} 1}$-CN genotype as an additional fixed factor in the statistical model, because this locus has been reported to have a strong effect on milk composition in goats (Martin et al., 2002).

The amplification and sequencing of the goat $L P L$ cDNA (GenBank accession number: DQ370053) allowed us to determine that the coding region is 1,437 bp long and encodes a protein of 478 AA (Figure 1). A BlastP search of the GenBank database revealed that the goat AA sequence displayed $99 \%$ identity with its ovine and bovine $L P L$ orthologous sequences. Moreover, the comparison of the goat $L P L$ amino acid sequence against the Prosite database (http://www.expasy.org/prosite/) with the ScanProsite software revealed several structural motifs that are common to lipases and other functionally related enzymes. These structural motifs are depicted in Figure 1 and include 1) the lipase domain that hydrolyzes the ester bond of triglycerides; 2) the polycystin-1, lipoxygenase, and alpha toxin (PLAT) domain that might be involved in protein-protein and protein-lipid interaction (Delrieu et al., 2002); 3) cysteine residues forming disulfide bridges (Yang et al., 1989); 4) N-glycosylation sites; and 5) the highly conserved active site triad ( $\mathrm{S} 162$, D186, and H271) responsible for enzyme catalysis (Mead et al., 2002).

The alignment of $L P L$ sequences from 18 goats belonging to the Murciano-Granadina, Malagueña, and 
Figure 1. Goat lipoprotein lipase (LPL) amino acid sequence. The black box indicates the lipase domain, the gray box indicates the polycystin-1, lipoxygenase, and alpha toxin domain, cysteine residues forming disulfide bridges are double underlined, sites of $\mathrm{N}$-glycosylation are underlined, and amino acids included in the active site triad are in bold, *; the Ser17Thr polymorphism is shown as \#.

Payoya breeds allowed us to identify the existence of 2 single nucleotide polymorphisms (SNP) located in the coding sequence (G50C, being position 1, the translation start site) and the $3^{\prime}$ untranslated region (UTR, C2094T). The G50C replacement was responsible for a Ser $\rightarrow$ Thr AA substitution at position 17 of the signal peptide. With almost 100 polymorphic sites (Merkel et al., 2002), the levels of polymorphism observed in the human $L P L$ gene are much higher than that reported in our work for the caprine ortholog. The extensive sequencing of intronic and other noncoding regions in the human $L P L$ gene, combined with the fact that a considerable number of individuals and populations have been screened in the search of mutations causing LPL deficiency, might explain this striking difference. We developed 2 primer extension protocols to type the G50C and C2094T mutations in 300 Murciano-Granadina goats and 117 goats from diverse breeds (Figure 2). A clear trend that emerged from the global analysis of the allelic frequencies was that the G50 and C2094 were the predominant alleles in all goat breeds, whereas C50 and T2094 displayed frequencies that ranged from 0 to 0.48 depending on the breed under consideration. This is in agreement with the usually unbalanced allelic frequencies of biallelic SNP observed in the human genome (Crawford et al., 2005). In this way, most SNP (64\% of all SNP) are rare, with a minor allele frequency below 0.05 (Crawford et al., 2005).

Significant differences in LPL activity in the Norwegian, Alpine, and Saanen breeds have been reported by several authors (reviewed in Chilliard et al., 2003) suggesting the existence of genetic factors that regulate the expression, localization, or activity of this enzyme. With the objective of investigating the possible functional role of the 2 mutations that we characterized in the goat $L P L \mathrm{cDNA}$, we performed an association analysis in a 130 Murciano-Granadina goat population for which diverse milk-related traits were registered (Table 2). We did not find any association between the C2094T SNP and milk traits. In contrast, we found suggestive differences among G50C geno- 


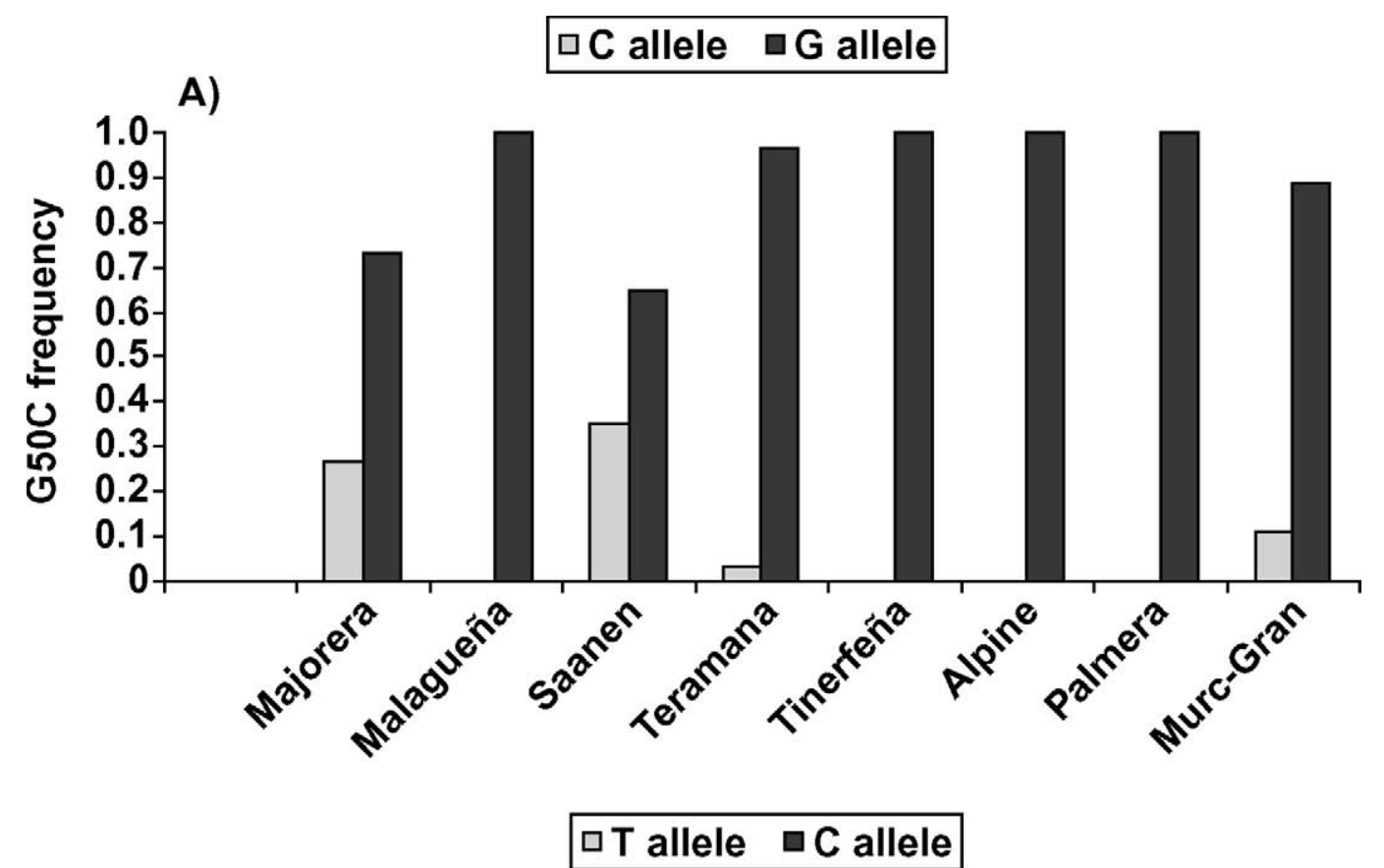

B)

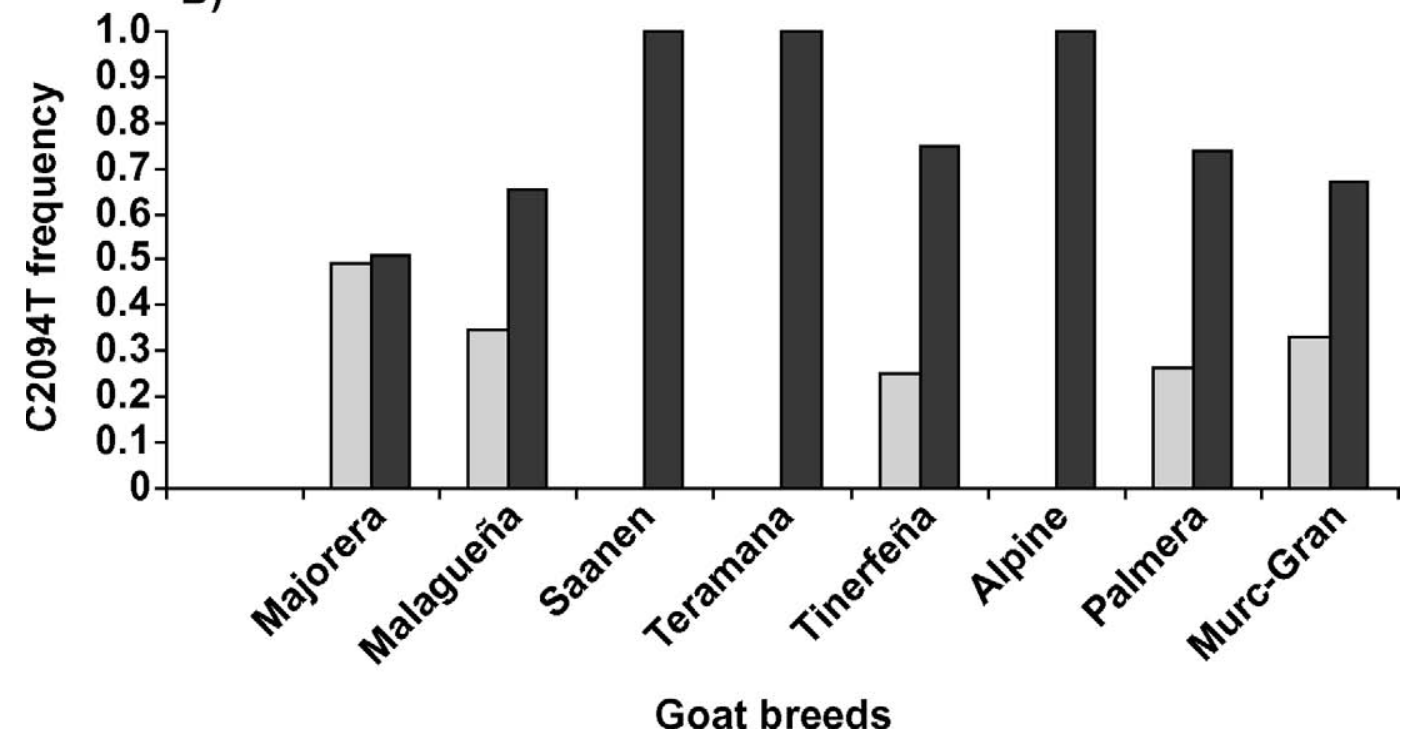

Figure 2. Allelic frequencies of the goat lipoprotein lipase gene (LPL) G50C (A) and C2094T (B) polymorphisms in 300 MurcianoGranadina (Murc-Gran) goats and in 117 Majorera, Palmera, Tinerfeña, Malagueña, Alpine, Saanen, and Teramana goats.

types with regard to milk fat $(P<0.05)$, in which a difference of $-0.55 \mathrm{~kg}$ of fat $/ 100 \mathrm{~kg}$ of milk was observed between the GC and GG genotypes. Interestingly, the G50 allele, which is favorable for fat content, is the most frequent allele in the analyzed goat breeds. Moreover, a tendency was observed for dry weight basis $(P$ $<0.1$ ). These associations are interesting because LPL mediates the hydrolysis of triglycerides carried by chylomicrons and very low density lipoproteins, the rate- limiting step in the delivery of free fatty acids to mammary gland and adipose tissues. In consequence, by controlling the delivery of fatty acids to mammary gland, LPL may affect milk fat content.

Mutations in the signal peptide, such as the one we found for goat LPL, may lead to an abnormal pattern of protein expression and localization. For instance, Zschenker et al. (2001) described a Gly $\rightarrow$ Arg substitution at position 5 of the lysosomal acid lipase signal 
Table 2. Least squares mean values corresponding to goat G50C and C2094T lipoprotein lipase gene genotypes for milk traits recorded from 130 Murciano-Granadina goats

\begin{tabular}{|c|c|c|c|c|c|}
\hline \multirow[b]{3}{*}{ Trait } & \multicolumn{5}{|c|}{ Goat $L P L$ genotypes ${ }^{1}$} \\
\hline & \multicolumn{2}{|c|}{ G50C SNP } & \multicolumn{3}{|c|}{ C2094T SNP } \\
\hline & GC & GG & $\mathrm{CC}$ & $\mathrm{TC}$ & $\mathrm{TT}$ \\
\hline Milk production, $\mathrm{kg} / \mathrm{d}$ & $1.98(0.23)$ & $2.03(0.20)$ & $1.99(0.21)$ & $1.96(0.21)$ & $2.05(0.25)$ \\
\hline Milk fat content, $\%$ & $6.12(0.39) *$ & $6.67(0.33)$ & $6.61(0.35)$ & $6.58(0.36)$ & $6.60(0.44)$ \\
\hline Milk protein content, \% & $3.54(0.15)$ & $3.61(0.12)$ & $3.66(0.14)$ & $3.71(0.14)$ & $3.60(0.17)$ \\
\hline Milk lactose content, $\%$ & $4.96(0.05)$ & $4.93(0.04)$ & $4.93(0.04)$ & $4.96(0.04)$ & $4.95(0.05)$ \\
\hline Milk total CN, \% & $2.94(0.13)$ & $2.99(0.11)$ & $2.96(0.11)$ & $2.98(0.11)$ & $2.98(0.14)$ \\
\hline$\alpha_{\mathrm{S} 1}-\mathrm{CN}$ content, $\mathrm{g} / \mathrm{kg}$ & $7.23(0.56)$ & $7.03(0.47)$ & $7.18(0.48)$ & $6.96(0.49)$ & $7.73(0.60)$ \\
\hline Dry weight basis, $\%$ & $14.21(0.48) \dagger$ & $14.81(0.41)$ & $14.70(0.43)$ & $14.73(0.44)$ & $14.67(0.54)$ \\
\hline LogSCC & $2.59(0.09)$ & $2.56(0.07)$ & $2.58(0.08)$ & $2.56(0.08)$ & $2.65(0.10)$ \\
\hline Clotting time, $\min$ & $39.49(2.56)$ & $41.24(2.09)$ & $41.09(2.31)$ & $40.72(2.34)$ & $39.40(2.94)$ \\
\hline Curd firming rate, $\mathrm{V}$ & $3.59(1.51)$ & $4.64(1.23)$ & $4.71(1.43)$ & $5.47(1.45)$ & $5.97(1.82)$ \\
\hline Curd firmness at $30 \mathrm{~min}, \mathrm{~V}$ & $3.35(1.99)$ & $5.37(1.62)$ & $5.37(1.89)$ & $6.23(1.92)$ & $6.99(2.43)$ \\
\hline Serum fat content, $\%$ & $0.92(0.24)$ & $0.84(0.19)$ & $0.89(0.23)$ & $0.84(0.22)$ & $0.89(0.30)$ \\
\hline Serum protein content, $\%$ & $1.00(0.11)$ & $0.94(0.09)$ & $0.99(0.10)$ & $0.91(0.09)$ & $0.86(0.13)$ \\
\hline Serum lactose content, $\%$ & $4.68(0.27)$ & $4.76(0.22)$ & $4.63(0.22)$ & $4.67(0.21)$ & $4.48(0.28)$ \\
\hline
\end{tabular}

${ }^{1}$ Standard errors of the least squares means corresponding to each genotype are indicated in parentheses; SNP = single nucleotide polymorphism .

$\dagger P<0.1 ; * P<0.05$.

peptide that involved a severe reduction of enzyme activity in culture supernatants but not in cell extracts. In humans, a huge number of polymorphisms have been found in the $L P L$ gene (Merkel et al., 2002), several of which are associated with the occurrence of chylomicronemia (for instance Gly188Glu) or, conversely, to an increased expression of the LPL enzyme (Ser447Stop). Currently, we do not know if the significant differences for fat content that we found for G50C genotypes are due to a differential $L P L$ allelic pattern of expression or, conversely, if this association is produced by linkage disequilibrium with an unidentified polymorphism with such effects. The measurement of mammary gland LPL activity and $L P L$ mRNA levels in goats with different $L P L$ G50C genotypes might be a very useful experimental approach for answering this question.

\section{ACKNOWLEDGMENTS}

This work was funded by a grant of the Spanish Ministry of Science and Technology (AGL2002-04304C03-02 GAN) and in part by a research scholarship to B. Badaoui from CIHEAM-IAMZ (Instituto Agronómico Mediterráneo de Zaragoza, Spain).

\section{REFERENCES}

Amills, M. 1996. Design and application of molecular techniques to analyse the effect of the goat $\alpha$ s1-casein polymorphism on production traits. PhD Thesis. Universitat Autonoma de Barcelona, Spain.

Amills, M., J. Capote, A. Tomàs, L. Kelly, G. Obexer-Ruff, A. Angiolillo, and A. Sànchez. 2004. Strong phylogeographic relation- ships among three goat breeds from the Canary Islands. J. Dairy Res. 71:257-262.

Amills, M., N. Jiménez, D. Villalba, M. Tor, E. Molina, D. Cubiló, C. Marcos, A. Francesch, A. Sànchez, and J. Estany. 2003. Identification of three single nucleotide polymorphisms in the chicken insulin-like growth factor 1 and 2 genes and their associations with growth and feeding traits. Poult. Sci. 82:1485-1493.

Badaoui, B., J. M. Serradilla, A. Tomàs, B. Urrutia, J. L. Ares, J. Carrizosa, A. Sànchez, J. Jordana, and M. Amills. 2007. Goat acetyl-coenzyme A carboxylase $\alpha$ : Molecular characterization, polymorphism and its association with milk traits. J. Dairy Sci. 90:1039-1043.

Barber, M. C., R. A. Clegg, M. T. Travers, and R. G. Vernon. 1997. Lipid metabolism in the lactating mammary gland. Biochim. Biophys. Acta 1347:101-126.

Bonnet, M., C. Leroux, Y. Chilliard, and P. Martin. 2000. Rapid communication: Nucleotide sequence of the ovine lipoprotein lipase cDNA. J. Anim. Sci. 78:2994-2995.

Chilliard, Y., A. Ferlay, J. Rouel, and G. Lamberet. 2003. A review of nutritional and physiological factors affecting goat milk lipid synthesis and lipolysis. J. Dairy Sci. 86:1751-1770.

Crawford, D. C., D. T. Akey, and D. A. Nickerson. 2005. The patterns of natural variation in human genes. Annu. Rev. Genomics Hum. Genet. 6:287-312.

Delrieu, I., C. C. Waller, M. M. Mota, M. Grainger, J. Langhorne, and A. A. Holder. 2002. PSLAP, a protein with multiple adhesive motifs, is expressed in Plasmodium falciparum gametocytes. Mol. Biochem. Parasitol. 1:11-20.

Edwards, W. D., S. E. Daniels, R. A. Page, C. P. Volpe, P. Kille, G. E. Sweeney, and A. Cryer. 1993. Cloning and sequencing of a full length cDNA encoding ovine lipoprotein lipase. Biochim. Biophys. Acta 1172:167-170.

Lien, S., L. Gomez-Raya, and D. I. Vage. 1995. A BsmAI polymorphism in the bovine lipoprotein lipase gene. Anim. Genet. 26:283-284

Martin, P., M. Szymanowska, L. Zwierzchowski, and C. Leroux. 2002. The impact of genetic polymorphisms on the protein composition of ruminant milks. Reprod. Nutr. Dev. 42:433-459.

Mead, J. R., S. A. Irvine, and D. P. Ramji. 2002. Lipoprotein lipase: Structure, function, regulation, and role in disease. J. Mol. Med. 80:753-769. 
Merkel, M., R. H. Eckel, and I. J. Goldberg. 2002. Lipoprotein lipase: Genetics, lipid uptake, and regulation. J. Lipid Res. 12:19972006.

Ramunno, L., G. Cosenza, M. Pappalardo, N. Pastore, D. Gallo, P. Di Gregorio, and P. Masina. 2000. Identification of the goat CSN1S1F allele by means of PCR-RFLP method. Anim. Genet. $31: 342-343$

Senda, M., K. Oka, W. V. Brown, and P. K. Qasba. 1987. Molecular cloning and sequence of a cDNA coding for bovine lipoprotein lipase. Proc. Natl. Acad. Sci. USA 84:4369-4373.
Tank, P. A., and D. Pomp. 1994. PCR-based Sau96I polymorphism in the bovine lipoprotein lipase gene. J. Anim. Sci. 11:3032.

Yang, C. Y., Z. W. Gu, S. A. Weng, T. W. Kim, S. H. Chen, H. J. Pownall, P. M. Sharp, S. W. Liu, W. H. Li, A. M. Gotto Jr 1989. Structure of apolipoprotein B-100 of human low density lipoproteins. Arteriosclerosis 1:96-108.

Zschenker, O., N. Jung, J. Rethmeier, S. Trautwein, S. Hertel, M. Zeigler, and D. Ameis. 2001. Characterization of lysosomal acid lipase mutations in the signal peptide and mature polypeptide region causing Wolman disease. J. Lipid Res. 42:1033-1040. 